\title{
Effect of Hot Dip Galvanized Steel Surface Chemistry and Morphology on Titanium Hexafluoride Pretreatment
}

\author{
Ville Saarimaa ${ }^{*}$, Antti Markkula², Kai Arstila ${ }^{3}$, Jere Manni' ${ }^{1}$, Jyrki Juhanoja1 \\ ${ }^{1}$ Top Analytica Oy, Turku, Finland \\ ${ }^{2}$ SSAB Europe Oy, Hämeenlinna, Finland \\ ${ }^{3}$ Department of Physics, University of Jyväskylä, Jyväskylä, Finland \\ Email: *Ville.Saarimaa@topanalytica.com
}

How to cite this paper: Saarimaa, V., Markkula, A., Arstila, K., Manni, J. and Juhanoja, J. (2017) Effect of Hot Dip Galvanized Steel Surface Chemistry and Morphology on Titanium Hexafluoride Pretreatment. Advances in Materials Physics and Chemistry, 7, 28-41.

https://doi.org/10.4236/ampc.2017.72004

Received: October 20, 2016

Accepted: February 6, 2017

Published: February 9, 2017

Copyright $\odot 2017$ by authors and Scientific Research Publishing Inc. This work is licensed under the Creative Commons Attribution International License (CC BY 4.0).

http://creativecommons.org/licenses/by/4.0/

\begin{abstract}
Titanium hexafluoride pretreatments are known to improve paint adhesion and function as a barrier between the coating and the hot dip galvanized (HDG) steel surface. Interactions at the zinc/pretreatment interface are of utmost importance for the formation of pretreatment layers and the corrosion resistance of color coated hot dip galvanized steels. Removal rate of inert aluminum oxide from HDG steel samples by chemical dissolution was studied. XPS measurements showed that the surface $\mathrm{Al}_{2} \mathrm{O}_{3}$ layer thickness decreased rapidly already at mild alkaline cleaning, while complete removal of $\mathrm{Al}$ required severe etching. Low reactivity of an $\mathrm{Al}_{2} \mathrm{O}_{3}$-rich surface was confirmed by impaired formation of a titanium hexafluoride pretreatment layer. Grain boundaries and deformation twinnings were shown to be of importance for the reactivity of the HDG surface and for the precipitation of the pretreatment chemical. Helium ion microscopy images and electron probe microanalysis (EPMA) of a pretreated sample showed accumulation of the pretreatment chemical at the grain boundaries. Al removal rate was fast at the deformation twinnings at the grain plateaus. Slow $\mathrm{Al}$ removal was observed at dendritic valleys and grain boundaries. The results increase understanding of the reactivity of hot dip galvanized steel surface.
\end{abstract}

\section{Keywords}

Hot Dip Galvanized Steel, Aluminum Oxide, Pretreatment, Surface Morphology, Helium Ion Microscopy

\section{Introduction}

Hot dip galvanized (HDG) zinc coatings are known for good formability and 
high corrosion resistance. HDG steel is coated in a continuous color coating line in order to improve the corrosion protection of the final product, provide desired functionality and for aesthetical reasons. Color coated HDG steel has wide range of applications from household appliances to construction industry. The various applications set different demands for the performance of the coated steel products. The degradation reactions (due to physical, chemical or biological degradation, oxidation or photo-oxidation) of polymer coatings are fairly well known [1], and polymer matrixes can be tailored according to the requirements of the end use environment. The corrosion properties of color coated steel are regulated by incorporating corrosion inhibitors into the coatings. The performance of different inhibitors has also been widely studied and the non toxic inhibitors have now mostly replaced the chromates [2] [3] [4] [5].

Coating adhesion on pretreated HDG surfaces depends mainly on physical bonds (dispersive and electrostatic forces) and chemical bonds (covalent, ionic, hydrogen and polar) [6]. In order to improve metal/coating adhesion, zinc coated steel is pretreated before color coating. Although the pretreatment layers are significantly thinner than the organic coatings, they are of crucial importance for the coating adhesion as well as for the corrosion resistance [7] [8] [9] [10] [11]. The corrosion resistance is strongly affected by the electrolytic environment that prevails at the metal/polymer interface [12] [13]. The term "barrier effect" is often used to describe the overall performance of the Cr-free pretreatments, indicating that the modern $\mathrm{Cr}$-free pretreatments lack the active corrosion resistance typical for chromates. Pretreatment solutions based on titanium or zirconium hexafluorides are widely used in the color coating industry for hot dip galvanized steel. The uniformity of a titanium hexafluoride pretreatment layer on the HDG surface has been shown to correlate with the humidity resistance of coated panels [14].

It remains a challenge to achieve the functional performance of chromate pretreatments with $\mathrm{Cr}$-free pretreatments, which increases the importance of better understanding of the molecular level interactions between the metal coating applied by hot dip galvanizing and the Cr-free pretreatments [15]. The effect of surface chemistry of zinc coatings to the performance of thin passivation and pretreatment layers has been to some extent discussed in earlier studies [7] [15] [16]. The surface topography and its effect on coating adhesion have also been addressed, but the studies have mostly concentrated on the effect of temper rolling [6].

In this study, the chemistry and morphology of HDG surfaces, as well as their effects on the alkaline cleaning and titanium hexafluoride pretreatment were evaluated.

\section{Materials and Methods}

Non temper rolled hot dip galvanized steel $(\sim 0.2 \% \mathrm{Al}$ in the zinc bath) with a total coating mass of $275 \mathrm{~g} \mathrm{Zn} / \mathrm{m}^{2}$ was obtained from SSAB Europe Oy. The HDG steel was obtained without protective oil. The laboratory pretreatments 
were carried out as follows. The alkaline cleaning solution was prepared in deionized water from powder (Gardoclean 338, Chemetall). The prepared solutions and the corresponding $\mathrm{pH}$ values of the solutions are shown in Table 1. The cleaning was performed by dipping the panels in a bath at $60^{\circ} \mathrm{C}$ for $4 \mathrm{~s}$, followed by two times of rinsing with deionized water $\left(60^{\circ} \mathrm{C}\right.$ for $\left.4 \mathrm{~s}\right)$ in separate baths. The cleaning procedure was repeated two times. The pretreatment chemical was applied by dipping the panels into the pretreatment chemical bath (15\% chemical concentration) for $4 \mathrm{~s}$, followed by removal of excess liquid by pressing with a Teflon rolling pin on a magnetic chuck. Finally, the panels were oven dried at $60^{\circ} \mathrm{C}$ for 5 minutes.

A mildly acidic pretreatment chemical (Bonderite M-NT 1455T, Henkel) containing titanium hexafluoride, manganese phosphate and organic polymer was used [12] [17]. The chemical was characterized by XPS (X-ray photoelectron spectroscopy). For the measurement, a microscopy glass slide was submerged in a pretreatment chemical solution sample for $30 \mathrm{~s}$. The XPS analysis was performed after air drying of the slide. An XPS spectrum is shown in Figure 1 and the atomic-\% concentrations of different elements are shown in Table 2.

A CG842 instrument (Schott, Germany) was utilized for measurement of $\mathrm{pH}$. Element analysis and depth profiling was performed using X-ray photoelectron

Table 1. Concentrations and $\mathrm{pH}$ values of the prepared alkaline cleaning solutions.

\begin{tabular}{cc}
\hline Gardoclean $338, \mathrm{~g} / \mathrm{L}$ & $\mathrm{pH}\left(60^{\circ} \mathrm{C}\right)$ \\
\hline 0.00 & 6.1 \\
0.03 & 9.4 \\
0.06 & 9.7 \\
0.10 & 9.9 \\
0.20 & 10.2 \\
0.30 & 10.3 \\
0.50 & 10.5 \\
1.00 & 10.8 \\
2.00 & 11.0 \\
4.00 & 11.2 \\
8.00 & 11.4 \\
\hline
\end{tabular}

Table 2. Characterization of the pretreatment chemical by XPS. Three parallel measurements were performed.

\begin{tabular}{ccc}
\hline Element & Atomic-\% & Stdev \\
\hline F1s & 30.2 & 0.5 \\
O1s & 26.4 & 0.8 \\
C1s & 15.7 & 1.2 \\
Mn2p3 & 13.8 & 1.6 \\
Ti2p & 6.3 & 0.4 \\
P2p & 5.2 & 0.4 \\
N1s & 2.4 & 1.1 \\
\hline
\end{tabular}




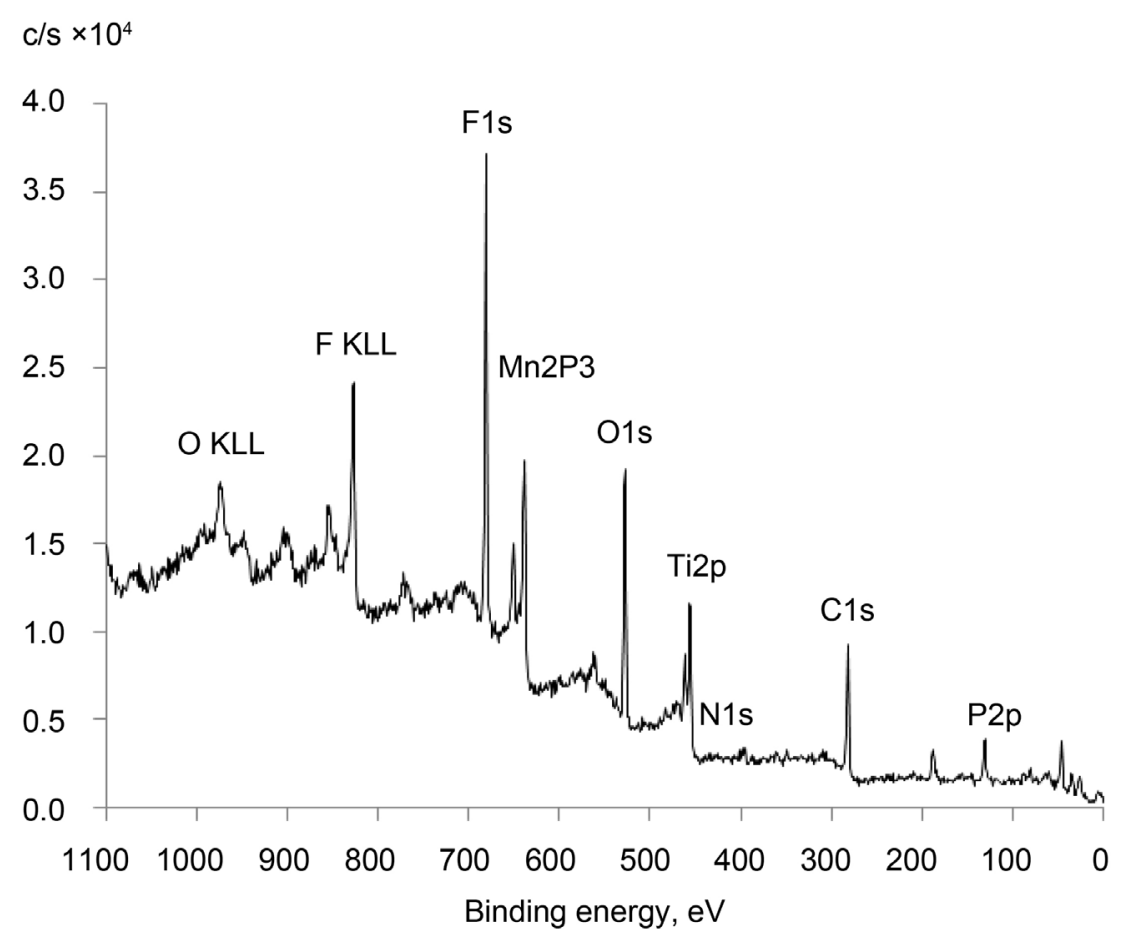

Figure 1. XPS spectrum recorded on a dried pretreatment chemical droplet on a glass slide.

spectroscopy (PHI Quantum 2000). The spectra were obtained using monochromated $\mathrm{Al} \mathrm{K} \alpha$ beam with a $200 \mu \mathrm{m}$ spot size. The sputtering was done with $\mathrm{Ar}^{+}$-ions, and the approximative sputtering rate was calculated using a $\mathrm{SiO}_{2}$ calibration standard. Before spectral acquisition, a mild $\sim 1 \mathrm{~nm}$ sputtering was employed in order to remove the surface carbon contamination. Helium ion microscopy was performed with a Carl Zeiss Orion NanoFab microscope using 30 $\mathrm{keV}$ helium beam energy and $0.4-0.5 \mathrm{pA}$ beam current. Secondary electrons were collected with an Everhart-Thornley detector at $500 \mathrm{~V}$ grid voltages. Working distance was $\sim 9 \mathrm{~mm}$ and dwell time was $50 \mu$ s per pixel. No line or frame averaging was used. Element mapping was performed with a time of flight secondary ion mass spectrometer (ToF-SIMS, PHI Trift II). The measurements were carried out at $25 \mathrm{kV}$ and 15 min measurement time. Mild sputtering with $\mathrm{Ga}^{+}$-ions at $15 \mathrm{kV}$ and $2 \mathrm{nA}$ for $250 \mathrm{~s} / \mathrm{mm}^{2}$ preceded the measurements. Element mapping was also carried out with an electron probe microanalyzer (EPMA) with wavelength-dispersive X-ray spectrometers (WDS) (JEOL JXA-8600). The maps were recorded at $15 \mathrm{kV}$ and $25 \mathrm{nA}$.

\section{Results and Discussion}

\subsection{Alkaline Cleaning}

In a continuous coil coating process, surface impurities are removed by leading the HDG sheet through alkaline cleaning steps before the pretreatment. During the alkaline cleaning, the surface is also activated by dissolving some of the inert $\mathrm{Al}_{2} \mathrm{O}_{3}$ [18] [19]. Removal of aluminum oxide as a function of alkaline cleaning 
solution concentration is shown in Figure 2. On the surface of non-etched HDG surface, over $30 \%$ of the atoms detected in the outermost few nanometers were aluminum. The rest was mostly oxygen with small contributions from zinc and carbon [20]. The surface aluminum concentration decreased when the sample was treated in an alkaline solution. The $\mathrm{Al} / \mathrm{Zn}$ atomic ratio decreased rapidly already at low concentrations of the cleaning solution. Similar trends have been obtained by increasing the treatment time and temperature [19]. In this study, the concentration of aluminum decreased much slower than the $\mathrm{Al} / \mathrm{Zn}$ ratio. The zinc signal, derived from metallic $\mathrm{Zn}$ below the $\mathrm{Al}_{2} \mathrm{O}_{3}$ layer, increased rapidly as the $\mathrm{Al}_{2} \mathrm{O}_{3}$ layer thickness decreased, which explains the difference. For instance, at $2 \mathrm{~g} / \mathrm{L}$ the decrease in $\mathrm{Al}$ atomic-\% was about $50 \%$ while the decrease in $\mathrm{Al} / \mathrm{Zn}$ atomic ratio was about $90 \%$. The $\mathrm{Al} / \mathrm{Zn}$ atomic ratio has been used in some studies to depict the aluminum content of a surface, since the $\mathrm{Al}$ atomic-\% values are generally rather small [6] [19]. Also, decrease in signal intensity due to local impurities such as carbon plays a lesser role if the $\mathrm{Al} / \mathrm{Zn}$ atomic ratio is considered instead of solely the $\mathrm{Al}$ atomic-\% data. Good adhesion and corrosion resistance properties have been reported with about $70 \%$ removal of $\mathrm{Al}$ [21]. A complete removal of $\mathrm{Al}$ requires severe etching and may not be process economically feasible [7] [19].

\subsection{XPS Depth Profiling of Pretreated Samples}

Samples with low removal of aluminum $(0.2 \mathrm{~g} / \mathrm{L})$ and high removal of aluminum $(4.0 \mathrm{~g} / \mathrm{L})$ were pretreated. XPS depth profiles of the different elements within the pretreatment layers are shown in Figure 3 and Figure 4 . Over 60 atomic-\% of the outermost surface was composed of carbon in both samples. The carbon signal decreased rapidly after mild sputtering, which confirmed that the carbon on the surface was present as a surface impurity. The true carbon signal,

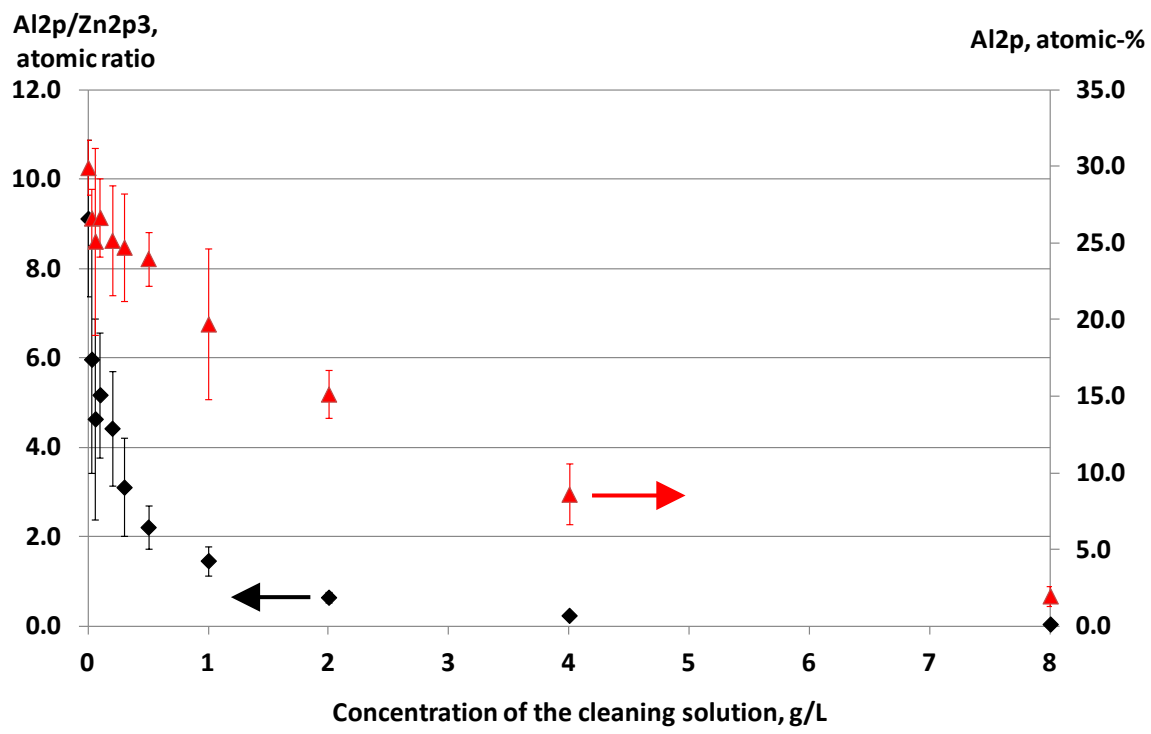

Figure 2. Dissolution of aluminum (oxide) from HDG samples as a function of the cleaning solution concentration. The results are average values of nine measurements. 

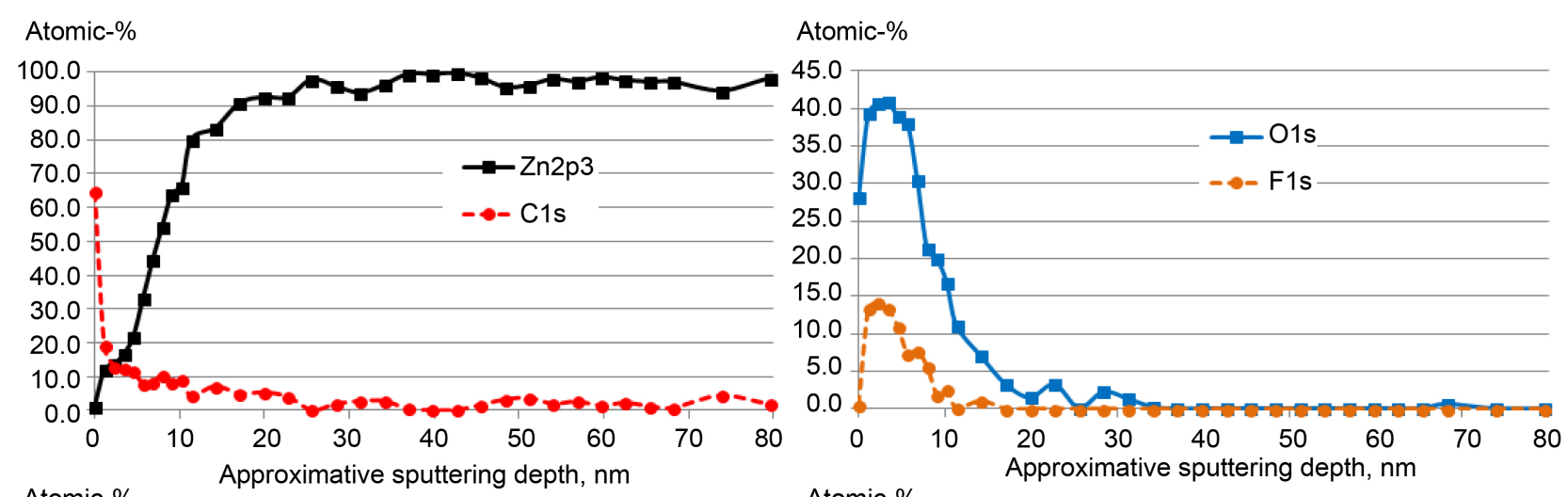

Atomic-\%

Atomic-\%
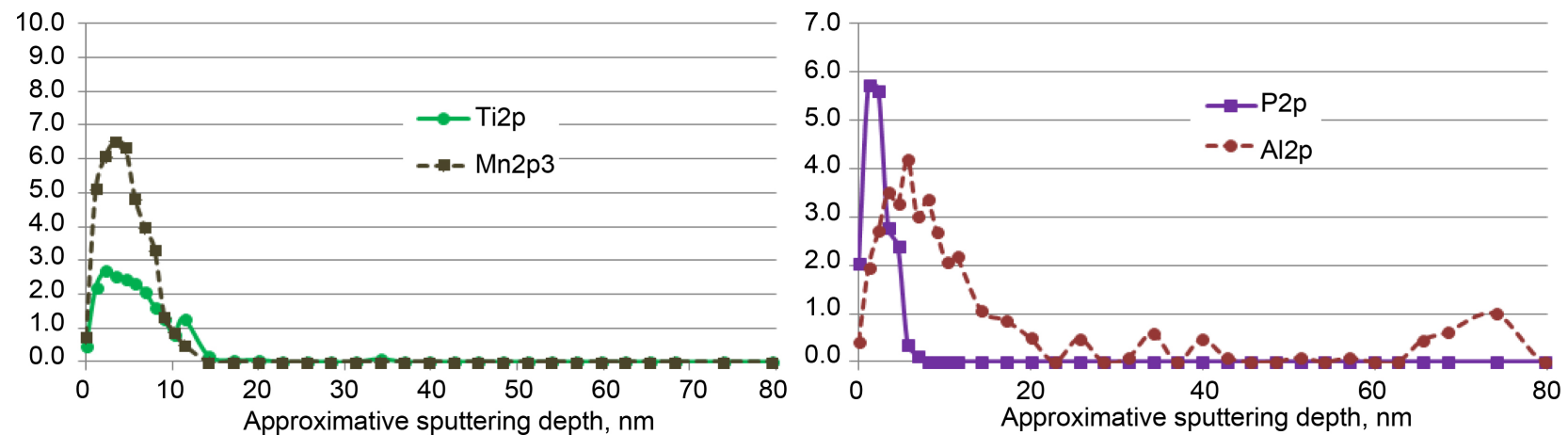

Figure 3. XPS depth profiles of the different elements in the pretreated layer on a non temper rolled hot dip galvanized steel sample (concentration of the cleaning chemical was $0.2 \mathrm{~g} / \mathrm{L}$ ). The results are averages of three parallel measurements.
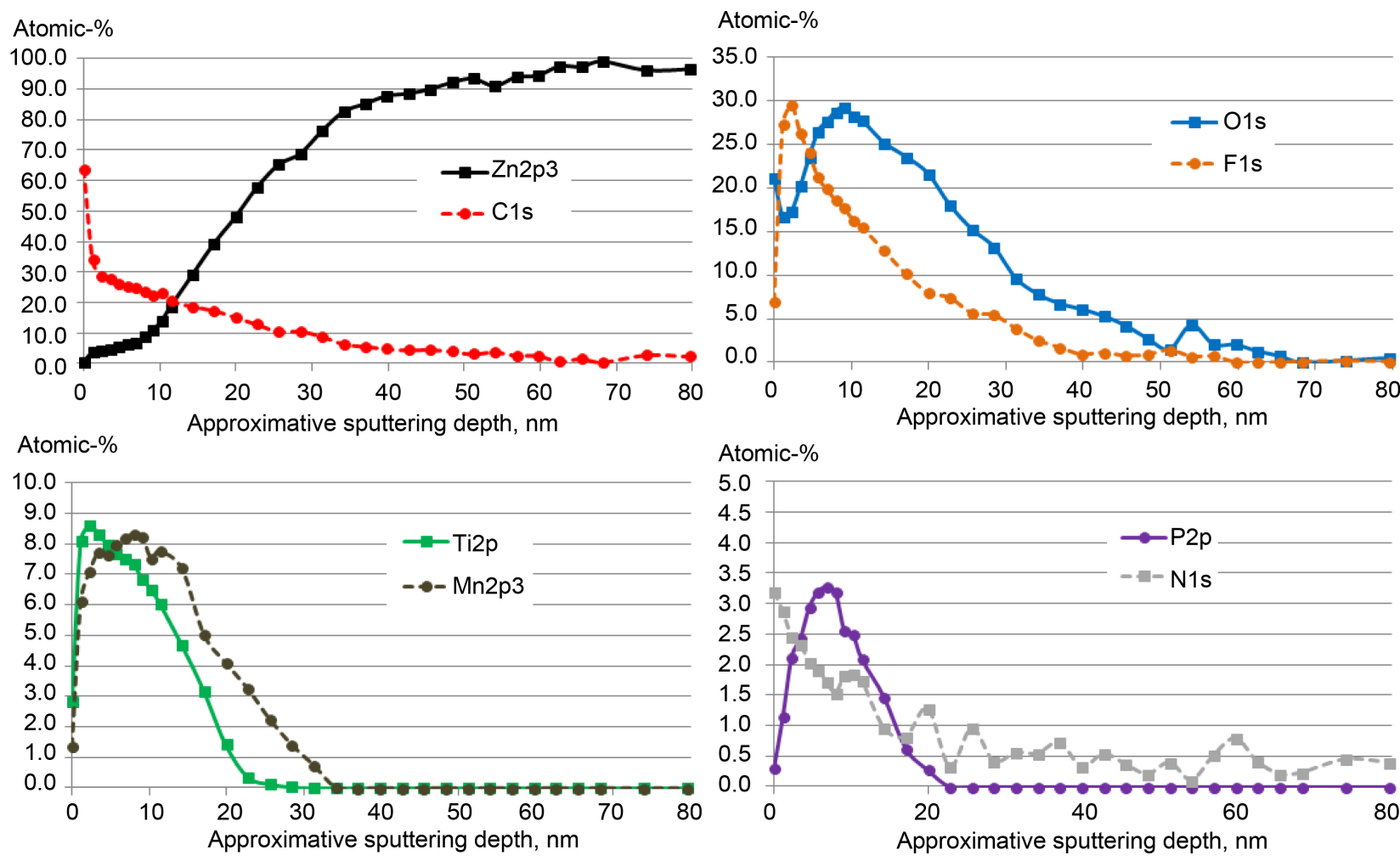

Figure 4. XPS depth profiles of the different elements in the pretreated layer on a non temper rolled hot dip galvanized steel sample (concentration of the cleaning chemical was $4.0 \mathrm{~g} / \mathrm{L}$ ). The results are averages of three parallel measurements. Al was not detected. 
representing the polymer in the pretreatment solution (Table 2), decreased steadily across the pretreatment layer. Bucheit and Hughes [22] reported the polymer to be more concentrated towards the surface of the pretreatment layer. However, in a study by Le Manchet et al. [23] the carbon originating in the polymer was present in a significant amount across the layer, which is in accordance with the results of this study (Figure 3 \& Figure 4). The pretreatment layer was also rich in oxygen. The presence of oxygen has been attributed to the presence of phosphates and metal hydroxides [23]. Fluorine was prominent on the surface of the pretreatment layer and its intensity decreased very rapidly, as seen especially in Figure 4. Residues of fluorine were, however, also present throughout the layer. In the dried pretreatment solution the Ti:F ratio was about $1: 5$, close to the stoichiometry of those elements in the pretreatment solution (Table 2). In the pretreated samples, a rough comparison of the Ti and $\mathrm{F}$ depth profile areas revealed that the Ti/F atomic- $\%$ ratio was close to $1: 2$ or $1: 3$, which is much lower than the stoichiometric 1:6 ratio. This confirms that the $\mathrm{TiF}_{6}^{2-}$ complex is broken as the pretreatment chemical reacts with the zinc surface [24]. In the sample cleaned at $0.2 \mathrm{~g} / \mathrm{L}$, phosphorous prevailed more on the surface of the pretreatment layer than manganese and titanium. The small amounts of nitrogen that could be observed in the pretreatment solution (Table 2) and in the well cleaned sample (Figure 4) could originate in an amine containing organic water-soluble polymer that is added in some pretreatment chemical compositions [17].

The approximative thickness of the pretreatment layer was significantly higher in the well cleaned sample (Figure 4) than in the sample with mild cleaning (Figure 3). Also, aluminum was detected only in the latter sample. Since the pretreatment step was identical for the both samples, it can be deduced that the sample with mild cleaning was less reactive than the well cleaned sample. Stellnberger et al. [25] showed by electrochemical quartz crystal microbalance measurements that the reactivity of a galvanized steel sample increases with alkaline cleaning. Similar results have been obtained in other pretreatment and coating studies [6] [7] [26]. The investigations are underway to establish a critical level of surface aluminum oxide removal for good coating adhesion.

\subsection{Helium Ion Microscopy of a Pretreated Sample}

Helium ion microscopy images of the pretreatment layer deposited on a sample after alkaline cleaning with a $4 \mathrm{~g} / \mathrm{L}$ concentration are shown in Figure 5. Grain boundaries have a dark appearance, which indicates strong presence of the pretreatment chemical [27]. Inside the grains there are remarkable contrast variations, which have earlier been shown to depend on the microscale thickness variations within the pretreatment layer [28]. Also deformation twinnings were seen within the grains. A close-up of the pretreated surface further highlights the microscopic thickness variations in the pretreatment layer, higher concentrations seen as darker spots. Deformation twinnings are seen on the surface. The surface of the twinnings is composed of wavy lines, and the edges of the twinnings are rather sharp. Formation of a deformation twinning is described as a 

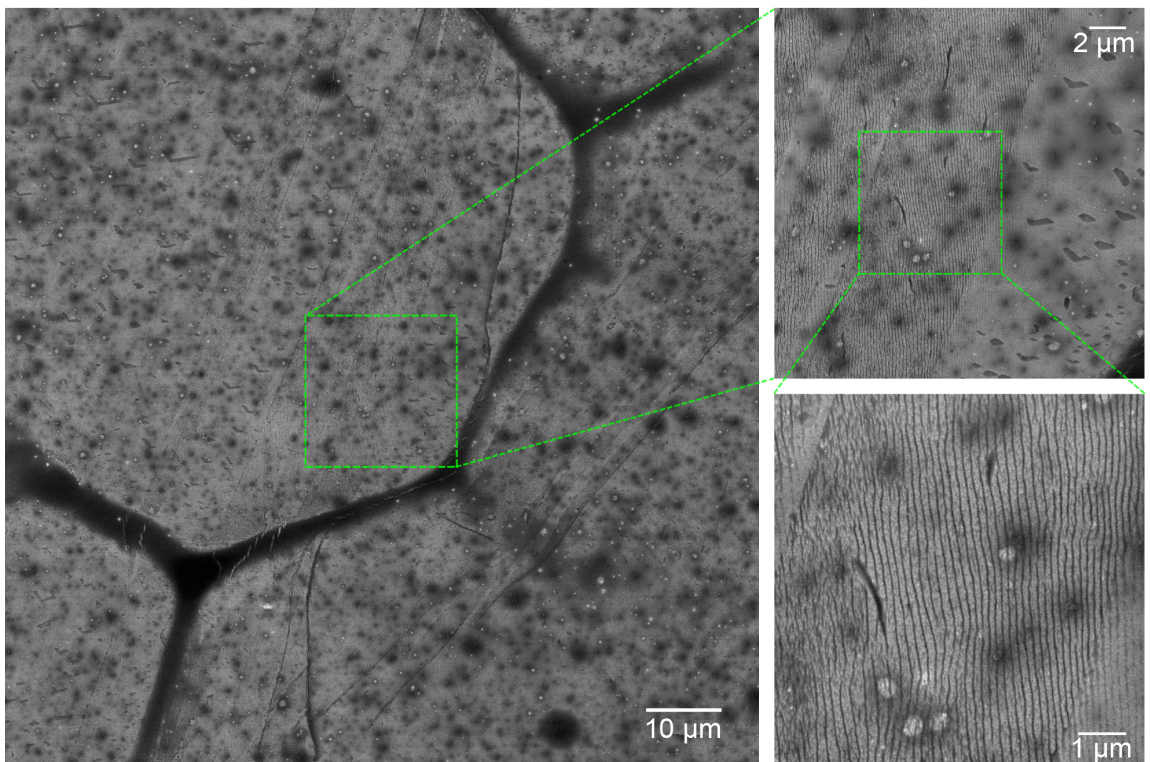

Figure 5. Helium ion microscopy images of a well cleaned (4 g/L), pretreated HDG sample.

homogeneous movement leading to macroscopic deformation accompanied by shuffling of atoms [29] [30]. The dislocations due to deformation take place at the atomic level, extending up to several atomic layers. The collective atomic movements are localized along discontinuity lines, which probably are the lines visible in the HIM images. Twinnings are typically in contact with at least one grain boundary and usually extend across the grain [29]. Also, some darker $\sim 1$ $\mu \mathrm{m}$ wide cavities in the zinc were observed. Additionally, bright unidentified sub-micrometer sized spots with significant size variation were visible beneath the pretreatment layer.

\subsection{Deformation Twinnings}

A variety of deformation modes can occur in zinc coatings [29] [31] [32]. At low strain levels $(<5 \%)$, the deformation occurs predominantly by twinning [30] [33] [34] [35]. About $1 \%$ tensile elongation takes place at the end of the zinc coating process [16] [31], causing extensive formation of deformation twinnings. The effect of deformation twinnings on the reactivity of the zinc surface was studied with selected samples after alkaline cleaning. At mild alkaline cleaning $(0.2 \mathrm{~g} / \mathrm{L})$ the deformation twinning that was easily observed in a light microscopy imagecould not be distinguished in ToF-SIMS element maps (Figure 6). The surface was covered by $\mathrm{Al}$ (oxide) and only trace amounts of $\mathrm{Zn}$ were detected. At stronger alkaline cleaning, $2 \mathrm{~g} / \mathrm{L}$, a twinning was seen also in ToF-SIMS element maps (Figure 7). In general, the $\mathrm{Al}$ counts were decreased and the $\mathrm{Zn}$ counts were increased when stronger alkaline cleaning was applied. Compared with the surrounding areas, at $2 \mathrm{~g} / \mathrm{L}$ the deformation twinning was depleted in $\mathrm{Al}$, while similar changes were not seen in the $\mathrm{Zn}$ element map. $\mathrm{Al}$ was also prominent in the dendritic valleys crossing the deformation twinning and in the grain boundary [36] [37]. This indicates a clear chemical difference in the surface composition of 

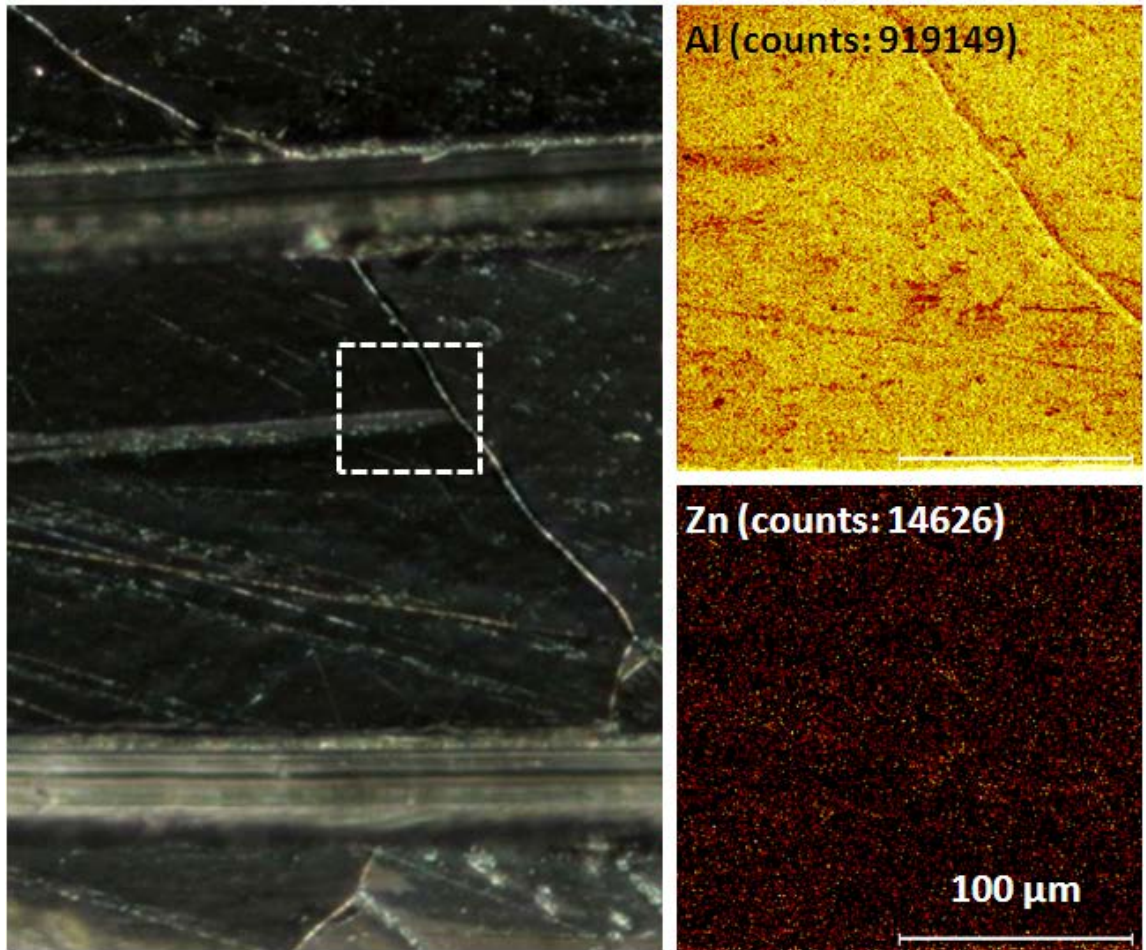

Figure 6. ToF-SIMS element maps of $\mathrm{Al}$ and $\mathrm{Zn}$ of a deformation twinning close to a grain boundary. Brighter color in the ToF-SIMS maps indicates higher intensity of the element. The sample was cleaned with a $0.2 \mathrm{~g} / \mathrm{L}$ cleaning solution prior to measurement. Light microscopy was employed for choosing of the imaging spot (image on the left).
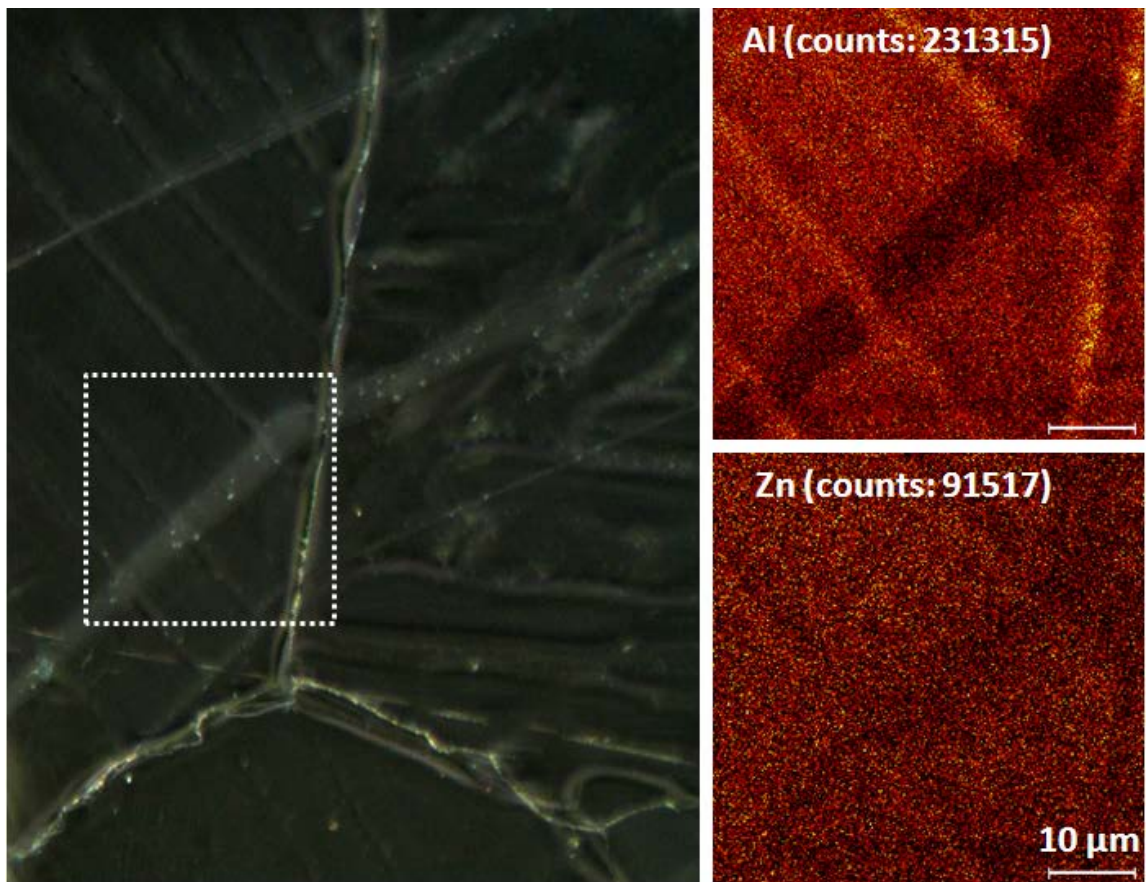

Figure 7. ToF-SIMS element maps of $\mathrm{Al}$ and $\mathrm{Zn}$ of a deformation twinning close to a grain boundary, intersected by dendrites. Brighter color in the ToF-SIMS maps indicates higher intensity of the element. The sample was cleaned with a $2 \mathrm{~g} / \mathrm{L}$ cleaning solution prior to measurement. Light microscopy was employed for choosing of the imaging spot (image on the left). 
the different structural details. The deformation by twinning has been proposed to cause a slight increase in surface roughness [34]. The higher reactivity of the twinning, seen in this study as stronger $\mathrm{Al}$ dissolution, could be due to disruption of the $\mathrm{Al}_{2} \mathrm{O}_{3}$ layer. At higher concentrations of the alkaline cleaning chemical, due to extensive removal of $\mathrm{Al}$, the twinnings could not be distinguished by ToF-SIMS anymore.

\subsection{Accumulation of Pretreatment Chemical in Grain Boundaries}

The origin of the dark appearance of the grain boundaries that was detected with HIM (Figure 5) was further studied with EPMA. Element maps were recorded at a grain boundary of the pretreated sample (cleaning at $4 \mathrm{~g} / \mathrm{L}$, followed by pretreatment) (Figure 8). Higher $\mathrm{Ti}, \mathrm{Mn}$ and $\mathrm{O}$ intensities were measured at the grain boundary than at the grain plateaus, confirming higher pretreatment coating weight at the grain boundaries. Greater surface roughness (depressions in a zinc coating) has been proposed to increase the coating weight deposited per unit of the apparent surface area due to increased reactive area during the treatment [38]. However, on the other hand the dendritic valleys and grain boundaries are often populated with high amounts of aluminum and other impurities rejected from the molten zinc during the solidification of the zinc coating [36]. Thus, the higher coating weight of the pretreatment chemical at the grain boundaries may also be a drying effect.

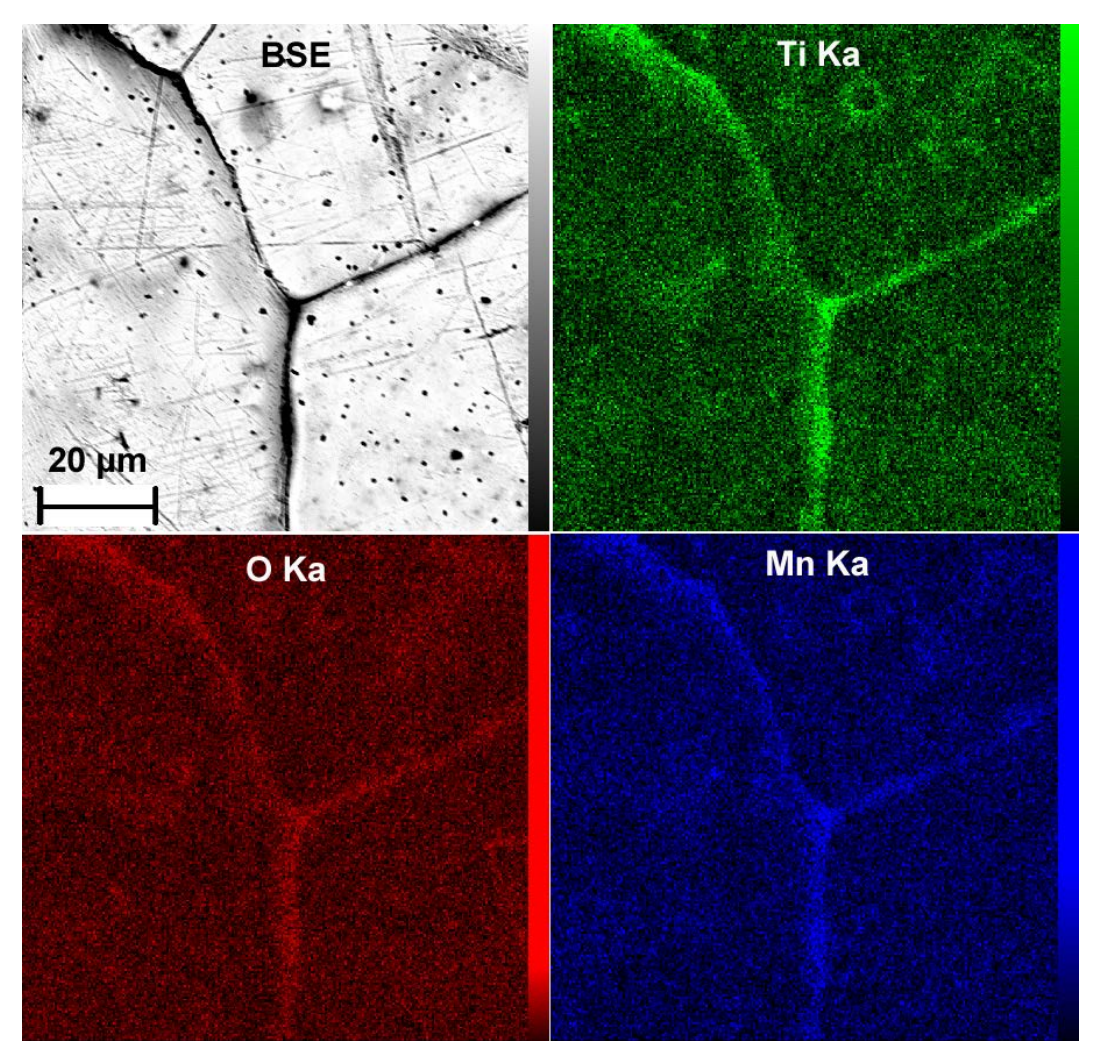

Figure 8. EPMA element maps measured on a grain boundary of a cleaned and pretreated HDG sample (sample treated with a $4 \mathrm{~g} / \mathrm{L}$ cleaning solution before pretreatment). Brighter color in the maps indicates higher intensity. 


\section{Conclusion}

Chemical composition and morphology of the outermost surface of hot dip galvanized steel strongly affect the reactivity of the surface and the formation of a titanium hexafluoride pretreatment layer. Residual $\mathrm{Al}_{2} \mathrm{O}_{3}$ is the most important factor affecting the reactivity of non-oiled HDG steel surfaces. The $\mathrm{Al} / \mathrm{Zn}$ atomic ratio decreased rapidly when HDG samples were exposed to mild alkaline cleaning, because the decrease in $\mathrm{Al}_{2} \mathrm{O}_{3}$ layer thickness strongly increased the $\mathrm{Zn}$ signal intensity. XPS measurements showed buildup of a thicker pretreatment barrier when the $\mathrm{Al}_{2} \mathrm{O}_{3}$ was removed. The dissolution of $\mathrm{Al}_{2} \mathrm{O}_{3}$ occurred more easily at deformation twinnings, which could be explained by an increased reactive surface area available for etching. On the other hand, the Al removal was slower at dendritic valleys and grain boundaries. Accumulation of the pretreatment chemical in the grain boundaries was confirmed by helium ion microscopy imaging and EPMA measurements. This could be due to higher reactivity of the grain boundaries, higher reactive area of the surface depressions, or a drying effect. The results of this study lay a foundation for our next study that will focus on evaluation of the effect of alkaline cleaning and different surface morphologies on paint adhesion and corrosion resistance of coated HDG samples.

\section{Acknowledgements}

Ari Peltola and Jorma Paavilainen from SSAB Europe Oy are acknowledged for their helpful comments. Kai Arstila acknowledges funding from the Finnish Centre of Excellence on Nuclear and Accelerator Based Physics by Academy of Finland (Project 251353).

\section{References}

[1] Billingham, N.C. (2000) Degradation and Stabilization of Polymers. In: Cahn, R.W., Haasen, P. and Kramer, E.J., Eds., Corrosion and Environmental Degradation, Vol. 2, Wiley-VCH, Weinheim, 470-507. https://doi.org/10.1002/9783527619306.ch19

[2] Barbucci, A., Delucchi, M. and Cerisola, G. (1998) Study of Chromate-Free Pretreatments and Primers for the Protection of Galvanized Steel Sheets. Progress in Organic Coatings, 33, 131-138. https://doi.org/10.1016/S0300-9440(98)00046-0

[3] Sinko, J. (2001) Challenges in Chromate Inhibitor Pigments Replacement in Organic Coatings. Progress in Organic Coatings, 42, 267-282. https://doi.org/10.1016/S0300-9440(01)00202-8

[4] Coughlin, R. (2004) Corrosion Inhibitors. In: Florio, J.J. and Miller, D.J., Eds., Handbook of Coating Additives, Second Edition, Marcel Dekker Inc., New York, 127-144.

[5] BelovI, I., Copeland, D., Fitzwater, B., Knapps, J. and Lewis, T. (2015) Development of Chromium (VI)-Free Coating Systems for Corrosion and Heat Protection. Proceedings of the Coatings Science International Conference, Noordwijk, The Netherlands, June 27-July 1 2015, 41-45.

[6] Puomi, P., Fagerholm, H., Rosenholm, J. and Sipilä, R. (2000) Effect of Skin Pass Rolling on the Primer Adhesion and Corrosion Resistance of Hot-Dip Galvanized (HDG) Steel. Journal of Adhesion Science and Technology, 14, 583-600. https://doi.org/10.1163/156856100742753 
[7] Maeda, S. (1996) Surface Chemistry of Galvanized Steel Sheets Relevant to Adhesion Performance. Progress in Organic Coatings, 28, 227-238. https://doi.org/10.1016/0300-9440(95)00610-9

[8] Critchlow, G.W. and Brewis, D.M. (1997) A Comparison of Chromate-Phosphate and Chromate-Free Conversion Coatings for Adhesive Bonding. The Journal of Adhesion, 61, 213-230. https://doi.org/10.1080/00218469708010523

[9] Briskham, P. and Smith, G. (2000) Cyclic Stress Durability Testing of Lap Shear Joints Exposed to Hot-Wet Conditions. International Journal of Adhesion and Adhesives, 20, 33-38. https://doi.org/10.1016/S0143-7496(99)00012-3

[10] Duarte, R.G., Bastos, A.C., Castela, A.S. and Ferreira, M.G.S. (2005) A Comparative Study between Cr(VI)-Containing and Cr-Free Films for Coil Coatings Systems. Progress in Organic Coatings, 52, 320-327. https://doi.org/10.1016/j.porgcoat.2004.05.011

[11] Zhu, L. and Ding, N. (2007) Corrosion Resistance of the Electro-Galvanized Steel Treated in a Titanium Conversion Solution. Surface and Coatings Technology, 201, 7829-7834. https://doi.org/10.1016/j.surfcoat.2007.03.024

[12] Ogle, K., Morel, S. and Meddahi, N. (2005) An Electrochemical Study of the Delamination of Polymer Coatings on Galvanized Steel. Corrosion Science, 47, 20342052. https://doi.org/10.1016/j.corsci.2004.08.017

[13] Öhman, M., Persson, D. and Jacobsson, D. (2011) In Situ Studies of Conversion Coated Zinc/Polymer Surfaces during Exposure to Corrosive Conditions. Progress in Organic Coatings, 70, 16-22. https://doi.org/10.1016/j.porgcoat.2010.09.012

[14] Saarimaa, V., Markkula, A., Juhanoja, J. and Skrifvars, B.J. (2015) Improvement of Barrier Properties of Cr-Free Pretreatments for Coil-Coated Products. Journal of Coatings Technology and Research, 12, 721-730.

https://doi.org/10.1007/s11998-015-9663-6

[15] Berger, R., Bexell, U., Grekh, T.M. and Hörnström, S.E. (2007) A Comparative Study of the Corrosion Protective Properties of Chromium and Chromium Free Passivation Methods. Surface and Coatings Technology, 202, 391-397. https://doi.org/10.1016/j.surfcoat.2007.06.001

[16] Mataigne, J.M., Vaché, V. and Repoux, M. (2009) Surface Chemistry and Reactivity of Skin-Passed Hot Dip Galvanized Coating. Metallurgical Research \& Technology, 106, 41-47. https://doi.org/10.1051/metal/2009013

[17] Liu, J., Dolan, S.E. and Scalera, P.A. (2003) Non-Chromate Conversion Coating Compositions, Process for Conversion Coating Metals, and Articles So Coated. Patent CA 2485124 C, US Patent 20030215653.

[18] Hörnström, S.E., Hedlund, E.G., Klang, H., Nilsson, J.O., Backlund, M. and Tegehall, P.E. (1992) A Surface Study of the Chemical Pretreatment before Coil Coating of Hot Dip Zinc-Coated Steel. Surface and Interface Analysis, 19, 121-126. https://doi.org/10.1002/sia.740190124

[19] Berger, R., Bexell, U., Stavlid, N. and Grekh, T.M. (2006) The Influence of AlkaliDegreasing on the Chemical Composition of Hot-Dip Galvanized Steel Surfaces. Surface and Interface Analysis, 38, 1130-1138. https://doi.org/10.1002/sia.2364

[20] Saarimaa, V., Markkula, A., Juhanoja, J. and Skrifvars, B.J. (2016) Novel Insight to Aluminum Compounds in the Outermost Layers of Hot Dip Galvanized Steel and How They Affect the Reactivity of the Zinc Surface. Surface and Coatings Technology, 306, 506-511. https://doi.org/10.1016/j.surfcoat.2015.11.014

[21] Puomi, P. and Fagerholm, H. (2001) Performance of Silane Treated Primed HotDip Galvanized Steel. Anti-Corrosion Methods and Materials, 48, 7-17. https://doi.org/10.1108/00035590110365273 
[22] Buchheit, R.G. and Hughes, A.E. (2003) Chromate and Chromate-Free Conversion Coatings. In: Cramer, S.D. and Covino, B.S., Eds., Corrosion: Fundamentals, Testing and Protection, ASM Handbook Volume 13A, 720-727.

[23] Le Manchet, S., Verchére, D. and Landoulsi, J. (2012) Effects of Organic and Inorganic Treatment Agents on the Formation of Conversion Layer on Hot-Dip Galvanized Steel: An X-Ray Photoelectron Spectroscopy Study. Thin Solid Films, 520, 2009-2016. https://doi.org/10.1016/j.tsf.2011.09.064

[24] Deck, P.D., Moon, M. and Sujdak, R.J. (1998) Investigation of Fluoacid Based Conversion Coatings on Aluminum. Progress in Organic Coatings, 34, 39-48. https://doi.org/10.1016/S0300-9440(98)00017-4

[25] Stellnberger, K.H., Wolpers, M., Fili, T., Reinartz, C., Paul, T. and Stratmann, M. (1997) Electrochemical Quartz Crystal Microbalance in Modern Corrosion Research. Faraday Discussions, 107, 307-322. https://doi.org/10.1039/a703236f

[26] Wolpers, M. and Angeli, J. (2001) Activation of Galvanized Steel Surfaces before Zinc Phosphating-XPS and GDOES Investigations. Applied Surface Science, 179, 281-291. https://doi.org/10.1016/S0169-4332(01)00296-3

[27] Lunder, O., Simensen, C., Yu, Y. and Nisancioglu, K. (2004) Formation and Characterisation of Ti-Zr Based Conversion Layers on AA6060 Aluminum. Surface and Coatings Technology, 184, 278-290. https://doi.org/10.1016/j.surfcoat.2003.11.003

[28] Saarimaa, V., Markkula, A., Juhanoja, J. and Skrifvars, B.J. (2014) Determination of Surface Topography and Composition of Cr-Free Pretreatment Layers on Hot Dip Galvanized Steel. Journal of Coatings Technology and Research, 1, 88-95.

[29] Ecob, N. and Ralph, B. (1983) The Effect of Grain Size on Deformation Twinning in a Textured Zinc Alloy. Journal of Materials Science, 18, 2419-2429. https://doi.org/10.1007/BF00541848

[30] Antonopoulos, J.G., Karakostas, T.H., Komninou, P.H. and Delavignette, P. (1988) Dislocation Movements and Deformation Twinning in Zinc. Acta Metallurgica, 36, 2493-2502. https://doi.org/10.1016/0001-6160(88)90195-2

[31] Lazik, S., Esling, C. and Wegria, J. (1995) Cracking in Zinc Layers on Continuous Galvanized Sheets-A Review. Textures and Microstructures, 23, 131-147. https://doi.org/10.1155/TSM.23.131

[32] Parisot, R., Forest, S., Pineau, A., Nguyen, F., Demonet, X. and Mataigne, J.M. (2004) Deformation and Damage Mechanisms of Zinc Coatings on Hot-Dip Galvanized Steel sheets: Part II. Damage Modes. Metallurgical and Materials Transactions $A, 35,813-823$. https://doi.org/10.1007/s11661-004-0008-9

[33] Marder, A.R. (2000) The Metallurgy of Zinc-Coated Steel. Progress in Materials Science, 45, 191-271. https://doi.org/10.1016/S0079-6425(98)00006-1

[34] Wichern, C.M., De Cooman, B.C. and Van Tyne, C.J. (2004) Surface Roughness Changes on a Hot-Dipped Galvanized Sheet Steel during Deformation at Low Strain Levels. Acta Metallurgica, 52, 1211-1222.

https://doi.org/10.1016/j.actamat.2003.11.005

[35] Culcasi, J.D., Elsner, C.I. and Di Sarli, A.R. (2009) Effect of Zinc Crystals Size on Galvanized Steel Deformation and Electrochemical Behavior. Materials Research, 12, 273-279. https://doi.org/10.1590/S1516-14392009000300005

[36] Biber, H.E. (1988) Scanning Auger Microprobe Study of Hot-Dipped RegularSpangle Galvanized Steel: Part I. Surface Composition of As-Produced Sheet. Metallurgical and Materials Transactions A, 19, 1603-1608. https://doi.org/10.1007/BF02674035

[37] Jaffrey, D., Browne, J.D. and Howard, T.J. (1980) The Cracking of Zinc Spangles on 
Hot-Dipped Galvanized Steel. Metallurgical and Materials Transactions B, 11, 631635. https://doi.org/10.1007/BF02670143

[38] Sankara, T.S.N. (2005) Narayanan, Surface Pretreatment by Phosphate Conversion Coatings-A Review. Reviews on Advanced Materials Science, 9, 130-177.

Submit or recommend next manuscript to SCIRP and we will provide best service for you:

Accepting pre-submission inquiries through Email, Facebook, LinkedIn, Twitter, etc. A wide selection of journals (inclusive of 9 subjects, more than 200 journals)

Providing 24-hour high-quality service

User-friendly online submission system

Fair and swift peer-review system

Efficient typesetting and proofreading procedure

Display of the result of downloads and visits, as well as the number of cited articles Maximum dissemination of your research work

Submit your manuscript at: http://papersubmission.scirp.org/

Or contact ampc@scirp.org 